\title{
The Effect of Equisetum Arvense (Horse Tail) Ointment on Wound Healing and Pain Intensity After Episiotomy:A Randomized Placebo-Controlled Trial
}

\author{
Azam Asgharikhatooni ${ }^{1}$; Soheila Bani ${ }^{2,}$; Shirin Hasanpoor ${ }^{3}$; Sakineh Mohammad Alizade ${ }^{3}$; \\ Yousef Javadzadeh $^{4}$
}

${ }^{1}$ Department of Midwifery, School of Nursing and Midwifery, Aras international branch, Tabriz University of Medical Sciences, Tabriz, IR Iran

${ }^{2}$ Neuroscience Research Center, Department of Midwifery, School of Nursing and Midwifery, Tabriz University of Medical Sciences, Tabriz, IR Iran

${ }^{3}$ Department of Midwifery, School of Nursing and Midwifery, Tabriz University of Medical Sciences, Tabriz, IR Iran

${ }^{4}$ Department of Pharmaceutics, Tabriz University of Medical Sciences, Tabriz, IR Iran

${ }^{*}$ Corresponding Author: Soheila Bani, Neuroscience Research Center, Department of Midwifery, School of Nursing and Midwifery, Tabriz University of Medical Sciences, Tabriz, IR Iran Tel: + 98-9144151456, E-mail: banisoheila@yahoo.com

Received: December 31, 2014; Accepted: January 28, 2015

Background: Episiotomy, a common surgical practice in midwifery, is accompanied with high levels of pain and discomfort for mothers. The importance of medicinal herbs and traditional medicine in wound healing cannot be neglected.

Objectives: Considering the positive effects and easy accessibility of Equisetum arvense, this study examined the effectiveness of topical application of Equisetum arvense ointment in wound healing, reduction of inflammation and pain relief after episiotomy in nulliparous mothers.

Patients and Methods: This double-blind clinical trial was performed on 108 postpartum nulliparous mothers (54 women in horsetail group and 54 women in placebo group) in Alzahra Educational-Medical Center(Tabriz, Iran). About $5 \pm 1$ and $10 \pm 1$ days after the childbirth, the primary outcomes of episiotomy, i.e. wound healing and pain intensity, were assessed based on redness, edema, ecchymosis, discharge and approximation of the edges (REEDA) scale and a visual analogue scale (VAS), respectively. The secondary outcomes evaluated in the current research were the number of used painkillers and the adverse events during the 10-day period of the study. Data was analyzed using independent $t$ and Mann-Whitney U tests.

Results: The case and control groups had no significant differences in for the mean wound healing score (5.0 \pm 1.6 vs. $4.1 \pm 1.6)$ and mean pain intensity ( $5.7 \pm 2.4$ vs. $5.3 \pm 2.2$ ) at baseline. During both follow-up sessions ( $5 \pm 1$ and $10 \pm 1$ days after delivery), the mean scores were significantly lower in the case group than the control group. The adjusted pain score difference (MD) after $5 \pm 1$ and $10 \pm 1$ days was -2.3 ( $95 \%$ CI:-3.2 to -1.3) and 3.8 (95\% CI:-4.7 to -3.0), respectively. The mean numbers of acetaminophen pills used in the control and case groups during the 10-day period of the study were $6.8 \pm 4.4$ and $11.6 \pm 7.1$, respectively $(\mathrm{P}<0.001)$.

Conclusions: According to our findings, 3\% Equisetum arvense ointment promoted wound healing and relieved pain during the 10-day period after episiotomy. Since this study was the first to assess the effects of Equisetum arvense ointment on wound healing and pain intensity following episiotomy in humans, further research is warranted to fully clarify the beneficial effects of prepared ointment.

Keywords: Equisetum; Horse; Tail; Episiotomy; Wound Healing; Pain

\section{Background}

Episiotomy is a common surgical practice in midwifery requiring an incision to the perineum to widen the vaginal opening, facilitate childbirth and prevent perineal injuries. Although the frequency of episiotomy has significantly reduced over the last 25 years, it is still practiced in Asian women due to shortness and strong tissue of their perineum, which increase the risk of large perineal tears $(1,2)$. Episiotomy is performed twice as often in Vietnamese-born women living in Australia than Australian-born women. The episiotomy rate was approximately 30\% in Vietnamese-born women and 15\% in Australian-born women (3). Women having their first birth have a higher risk of episiotomies (4). The prevalence of episiotomy in Asian countries is $42.9 \%$ of all childbirths in Nepal, $85 \%$ in Hong Kong and 100\% of nulliparous childbirths in
Taiwan $(2,5)$. Based on the previous studies, the prevalence of episiotomy in Iran is almost 100\% (6). Evidence accumulated showed that episiotomies prevent anterior perineal lacerations (which carry minimal morbidity), but fail to accomplish any of other maternal or fetal benefits traditionally ascribed, including prevention of perineal damage and its sequelae, prevention of pelvic floor relaxation and its sequelae and protection of newborn from either intracranial hemorrhage or intrapartum asphyxia (7). Episiotomy increased the risk of perineal pain and wound healing problems in the postpartum period (8). Postpartum is a sensitive time when mothers must juggle their own recovery while dealing with the needs of their newborns. Effective pain relief is a major aspect of postpartum care positively affecting women's life (9).

Copyright ( 2015, Iranian Red Crescent Medical Journal. This is an open-access article distributed under the terms of the Creative Commons Attribution-NonCommercial 4.0 International License (http://creativecommons.org/licenses/by-nc/4.0/) which permits copy and redistribute the material just in noncommercial usages, provided the original work is properly cited. 
Herbal products have gained increasing popularity in the last decade and are now used by approximately $20 \%$ of the population (10). The use of natural products is very common among non-industrialized societies, because these remedies are more accessible and affordable than modern pharmaceuticals. In developed countries, use of herbal products has been recently increased as scientific evidence about their effectiveness has become broadly available(11). Equisetum arvense, one of the oldest medicinal herbs, is a perennial pteridophyte with black rhizomes and two types of stems (spring and summer stems). It grows spontaneously in light sandy soils and is distributed in Europe, Africa, South America, Southern Asia, Turkey and Iran (12). It contains various chemical compounds such as silicic acid, linoleic acid, oleic acid, stearic acid, linolenic acid and traces of alkaloids (e.g. nicotine, equisetin and palustrine), glucoside, flavonoids, saponosides, calcium carbonate, potassium sulfate, potassium chloride, manganese chloride, iron, manganese and calcium phosphate, which can have medicinal applications. Moreover, one kilogram of fresh Equisetum arvense contains $200-260 \mathrm{~mL}$ of vitamin C (12). This plant has been used for several medicinal purposes including wound healing (due to its free silica), strengthening of the bones, teeth, nails and hair, gout reduction, urinary tract stone prevention, controlling nosebleeds and treatment of urinary tract and prostate complications and menorrhagia and rheumatoid arthritis. It has also had application as an antiseptic, anti-inflammatory, antioxidant, diuretic, anticonvulsant and anticancer agent. Moreover, the plant has been shown to have anti-diabetic properties and beneficial effects on reducing urinary creatinine in rats. Aqueous and ethanolic extracts of Equisetum arvense possess antimicrobial effects and can affect Staphylococcus, Bacillus, Escherichia coli, Klebsiella and Candida (12-19), and has antioxidant effects (20). In a study on rats, Ozay et al. found that Equisetum arvense promoted the dermis and epidermis reconstruction, vascularization and granulation tissue thickness after 14 days (14). In a study on the histometry and histopathology of skin wound healing in rabbits, Ashrafi et al. reported Equisetum arvense ointment to reduce wound size more effectively than zinc oxide ointment. Furthermore, the overall wound healing in the second and third weeks was more favorable using Equisetum arvense ointment (13). Apparently, the importance of medicinal herbs and traditional medicine in wound healing cannot be neglected. Despite proved benefits and easy accessibility of Equisetum arvense, the restorative and analgesic effects of this plant on humans have not been assessed to date.

\section{Objectives}

Therefore, this study attempted to examine the effectiveness of topical application of Equisetum arvense ointment in wound healing, inflammation reduction and pain relief after episiotomy in nulliparous mothers.

\section{Patients and Methods}

This double-blind clinical trial was performed on 108 postpartum nulliparous mothers (54 women in horsetail group and 54 women in placebo group) in Alzahra Educational-Medical Center (Tabriz, Iran) during 2013 14. Nulliparous mothers with mediolateral episiotomy willing to participate were recruited in the study if they aged 18-35 years, did not smoke cigarettes or use narcotics and psychotropic substances (according to the mothers and their documented records), gave birth to a singleton and did not have an assisted vaginal delivery. Women who had used anti-inflammatory drugs or anticoagulants during pregnancy (based on selfreports) or had a history of diseases known to disturb wound healing (e.g. systemic, heart, and renal diseases, coagulation disorders, immune deficiency, connective tissue disorders, diabetes, anemia, mental illnesses and hemophilia) were not included. Likewise, mothers who adhered to a specific diet (according to their own reports), had anemia during pregnancy (hemoglobin $<11.5 \mathrm{~g} / \mathrm{dL}$ ), developed early bleeding after delivery, had a history of vaginal examinations and manipulations after delivery, prolonged rupture of the amniotic sac (over 18 hours) and had undergone extended episiotomy (incision size $>3-4 \mathrm{~cm}$ ) or vaginal/perineal restoration surgeries were not recruited. Finally, women's ability to come to the mentioned hospital five and 10 days after childbirth was necessary for their participation. Both groups (placebo and Horsetail groups) were similar regarding sociodemographic and reproduction characteristics. Upon approval by the Ethics Committee of the Research and Technology Deputy of Tabriz University of Medical Sciences (ethical code: 9242) and registering the study in the Iranian Registry of Clinical Trials (ID: IRCT201305277618N5- July 29, 2013), a letter of introduction was received from the Research Deputy of the mentioned university. Afterward, eligible women were asked to provide written consent and complete form No.1 (containing sociodemographic and fertilityrelated information). Toassess the primary outcomes of episiotomy, redness, edema, ecchymosis, discharge and approximation of the edges (REEDA) were evaluated. Moreover, pain intensity was measured using a visual analogue scale (VAS) before the intervention, $5 \pm 1$ days after delivery (in the medical center where the mothers presented) and $10 \pm 1$ days after the childbirth (in the midwifery clinic where sampling was performed). The secondary outcomes were the number of used painkillers and adverse events during the first10 days after delivery. To prepare the sterile Equisetum arvense ointment, the plant was purchased from the pharmaceutical market in Tabriz and its authenticity was verified. Plant extract was then prepared using hydroalcoholic solvents (containing ethanol) in the herbarium of the School of Pharmacy in Tabriz. Afterward, empty metal tubes were sterilized through dry heating. The ointment base was 
then poured into the ointment filling machine and the temperature was increased to melt the base. During gradual reduction in the temperature of the base, the concentrated plant extract was added to the base (before it became firm). After thorough stirring of the mixture, the sterile tubes were filled under aseptic conditions and ultimately packed. The sterile placebo ointment, prepared using vaseline as the base and a few drops of Equisetum arvense extract, was packed in tubes exactly similar to those containing the Equisetum arvense ointment. A randomized block design (with block sizes of 4 and 6) was used to assign participants to receive either the Equisetum arvense ointment (case group) or the placebo ointment the control group). An allocation ratio of 1:1 was maintained during the grouping process. To ensure blindness, 40 grams Equisetum arvense or placebo ointment tubes were placed in sealed opaque envelopes numbered sequentially. An individual, who was not involved in the sampling or data collection and analysis, prepared the envelops. Moreover, the sequence of the allocation was determined using the Randomizer software. Therefore, only one person was aware of the type of administered drug, and the participants, researchers, data collectors and analyzers were blinded to the grouping. The researchers provided the participants with the ointments, a form to record the number of painkillers used from the baseline until the 10th day of the intervention, a pamphlet on how to apply the drug and a form containing the probable side effects of the ointment and the researcher's phone number. The subjects were recommended to use ointments after taking a shower and according to the instructions in the pamphlet. In brief, they were instructed to thoroughly wash their hands and perineum, dry them with a clean tissue, cover the incision site with a knuckle of ointment and wear a sanitary napkin after 1-2 minutes. They were supposed to perform the described procedure twice a day at $12 \pm 2$ hour intervals for 10 days. The researcher called the mothers every day to ensure the correct application of ointments and recorded the quantity and quality of the used ointment. The mothers were asked to visit Alzahra Educational-Medical Center $5 \pm 1$ and $10 \pm 1$ days after the intervention for perineal examination and assessment of wound healing and pain intensity (performed by the researcher). Each participant was provided with 20 acetaminophen $500 \mathrm{mg}$ pills and a form for recording the type and number of painkillers taken during the intervention. The forms were collected on subjects' last visit to the hospital (on the 10th day). To minimize the number of subjects lost-to-follow-up, the examinations on day $5 \pm 1$ were conducted at the healthcare center where the mothers were supposed to take their infants for thyroid screening. However, the second follow up session (on day $10 \pm 1$ ) was held in the local clinic where the participants had been selected. The sample size was determined based on the available studies in Iran (19) while assuming $\mathrm{m} 1=4.0, \mathrm{~m} 2=3.2$, $\mathrm{sd} 1=\mathrm{sd} 2=1.43$ and $\beta=20 \%$. After entering data in Stata 9.2 (Stata Corp LP, Texas, USA), the number of subjects in each group was calculated as 49 mothers. However, considering a probable sample loss of $10 \%$, the sample size was increased to 54 mothers in each group. All statistical analyses were performed using SPSS for Windows 13.0 (SPSS Inc., Chicago, IL, USA) at a significance level of 0.05. Normal distribution of quantitative variables in each group was confirmed by one-sample KolmogorovSmirnov tests. Independent t-tests were applied to compare the two groups for wound healing (REEDA score) before the intervention and $5 \pm 1$ days after the intervention. Mann-Whitney U test was conducted to compare the two groups $10 \pm 1$ days after the intervention and compare the mean REEDA sub-scores. Independent $t$ and Mann-Whitney tests were used to compare baseline pain intensity scores of the two groups with scores $5 \pm 1$ and $10 \pm 1$ days after the intervention, respectively.

\section{Results}

This study was performed on 108 nulliparous mothers (in two equal groups) in the postpartum unit of Alzahra Educational-Medical Center. Although 174 postpartum women were initially identified, 66 women were excluded due to their ineligibility. Two participants were absent for the follow-up session on the 10th day. One woman in the case group did not show up due to her husband's disagreement and one woman in the control group could not participate due to her infant's illness. The follow-up was completed for both groups $5 \pm 1$ and $10 \pm 1$ days after the intervention. Each group comprised 54 women before and $5 \pm 1$ days after the intervention, but 53 women $10 \pm 1$ days after the intervention (according to the flowchart). Table 1 summarizes sociodemographic characteristics of participants. The two groups were not significantly different for education level, occupation, husband's occupation, income, household size and type of toilet. The mean age of participants was $23.4 \pm 4.5$ years. Most subjects were housewives (98\%) and had a low household income (56\%). Most cases (87\%) and controls (91\%) used squat toilets. The primary outcomes in this study included the extent of wound healing and pain intensity after episiotomy. The mean baseline REEDA score was $5.0 \pm 1.6$ in the case group and 4.1 \pm 1.6 in the control group. The healing score in the case group was significantly lower than that in the control group both on day $5 \pm 1$ (-1.1; 95\% CI:-1.7 to -0.6) and day $10 \pm 1$ (-2.6; $95 \%$ CI:-3.2 to - 2.1) (Table 2 ). The reduction in REEDA score 10 days after delivery was $86 \%$ in the case group and $15 \%$ in the control group. There was a significant difference between the two groups for redness at baseline $(\mathrm{P}=0.04)$ and $10 \pm 1$ days after the intervention $(\mathrm{P}<0.001)$. The two groups were also significantly different for edema at baseline $(P=0.002)$ and $5 \pm 1$ and $10 \pm 1$ days after the intervention ( $\mathrm{P}<0.001$ for both). However, the scores of the two groups regarding ec- 


\section{Asgharikhatooni A et al.}

chymosis, discharge and approximation between the two edges were not significantly different. On the other hand, 10 days after the intervention, redness, edema, ecchymosis, discharge and approximation scores were zero in $85 \%, 75 \%, 100 \%, 4 \%$ and $74 \%$ of the cases, respectively. The corresponding values in the control group were $34 \%, 7 \%, 96 \%, 11 \%$ and $58 \%$. At baseline, the mean pain intensity in the case and control groups was $5.7 \pm 2.4$ and $5.3 \pm 2.2$, respectively. On day $5 \pm 1$, the mean pain intensity decreased by $14 \%$ in the case group, but increased by $34 \%$ in the control group. On day $10 \pm 1$, the mean pain intensity in the case and control groups reduced by $86 \%$ and $13 \%$, respectively. The adjusted pain score difference (MD) after $5 \pm 1$ and $10 \pm 1$ days were -2.3 (95\% CI:-3.2 to -1.3) and 3.8 (95\% CI:-4.7 to -3.0), respectively (Table 2 ). The secondary outcomes evaluated in the current research were the number of used painkillers and adverse events during the 10-day period after delivery. The mean numbers of acetaminophen pills used by the case and control groups were $6.8 \pm 4.4$ and $11.6 \pm 7.1$, respectively ( $P$ $<0.001$ ). The mean number of diclofenac suppositories used in the above-mentioned groups were $1.1 \pm 2.2$ and $3.7 \pm 3.5$, respectively $(\mathrm{P}<0.001)$. The participants were asked to visit the researcher at the clinic in case of any adverse events during the 10-day period of the study. Clinical symptoms of the participants, including fever, were measured by the researcher. The participants were referred to the physician of the medical center if necessary. The adverse events experienced by the case and control groups are presented in Table 3.

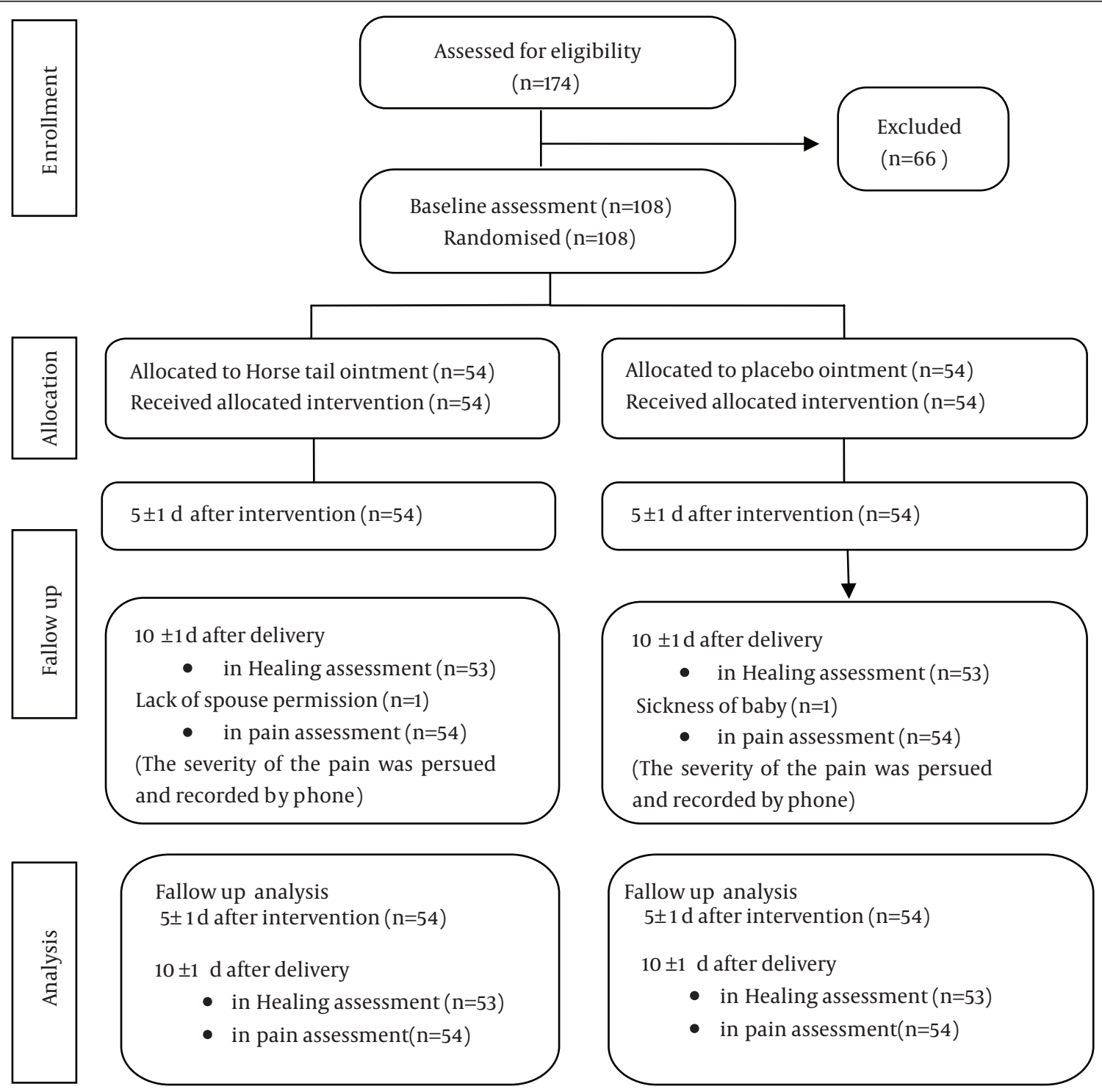

Figure 1. Flowchart of the Study 
Asgharikhatooni A et al.

Table 1. Socio-Demographic and Reproductive Characteristics of Participants ${ }^{\text {a }}$

\begin{tabular}{|c|c|c|}
\hline Characteristics & Horse Tail Group $(n=54)$ & Placebo Group $(n=54)$ \\
\hline Age, $y$ & $23.3 \pm 4.4$ & $23.2 \pm 4.7$ \\
\hline Body mass index, $\mathrm{kg} / \mathrm{m}^{2}$ & $23 \pm 4$ & $24 \pm 3$ \\
\hline External length of Episiotomy, cm & $3.7 \pm 0.4$ & $3.7 \pm 0.5$ \\
\hline Number of skin stitches & $4.4 \pm 0.8$ & $4 \pm 0.8$ \\
\hline Weight of newborn, gr & $3140.7 \pm 400.8$ & $3196.1 \pm 375.3$ \\
\hline Job, house wife & $52(96)$ & $54(100)$ \\
\hline Income upper than spent & 0 & $1(2)$ \\
\hline Income equal spent & $23(43)$ & $23(43)$ \\
\hline Income lower than spent & $31(56)$ & $30(56)$ \\
\hline Family number (1-3) & $42(78)$ & $45(83)$ \\
\hline Family number (4-6) & $10(18)$ & $6(11)$ \\
\hline Family number $>6$ & $2(4)$ & $3(6)$ \\
\hline Toilet type, at squatting position & $47(87)$ & $49(91)$ \\
\hline
\end{tabular}

${ }^{\mathrm{a}}$ Data are presented as No. (\%) or Mean \pm SD.

Table 2. Comparison of Healing Status and Pain Between the Study Groups at Different Time Points a, b, c

\begin{tabular}{|c|c|c|c|c|c|c|}
\hline \multirow[b]{2}{*}{ Group } & \multicolumn{3}{|c|}{ Healing Status (REEDA Scale, 0-15) } & \multicolumn{3}{|c|}{ Pain (VAS, 0-10) } \\
\hline & Baseline & $\begin{array}{l}(5 \pm 1) d \text { after } \\
\text { intervention }\end{array}$ & $\begin{array}{c}(10 \pm 1) d \text { after } \\
\text { delivery }\end{array}$ & Baseline & $\begin{array}{l}(5 \pm 1) d \text { after } \\
\text { intervention }\end{array}$ & $\begin{array}{c}(10 \pm 1) \text { d after } \\
\text { delivery }\end{array}$ \\
\hline Horsetail & $5.0 \pm 1.6$ & $2.9 \pm 1.4$ & $0.8 \pm 1.3$ & $5.7 \pm 2.4$ & $4.9 \pm 2.4$ & $0.8 \pm 1.7$ \\
\hline Placebo & $4.1 \pm 1.6$ & $4.0 \pm 1.4$ & $3.5 \pm 1.6$ & $5.3 \pm 2.2$ & $7.1 \pm 2.4$ & $4.6 \pm 2.6$ \\
\hline Mean difference (95\% CI) & $0.9(0.3$ to 1.6$)$ & $-1.1(-1.7--0.6)$ & $-2.6(-3.2--2.1)$ & $0.4(-0.5-1.3)$ & $-2.3(-3.2--1.3)$ & $-3.8(-4.7-3.0)$ \\
\hline P Value & $0.003 t^{d}$ & $\mathrm{P}<0.001$ & $\mathrm{P}<0.001$ & $0.526 \neq{ }^{\mathrm{e}}$ & $\mathrm{P}<0.001$ & $\mathrm{P}<0.001$ \\
\hline
\end{tabular}

${ }_{\mathrm{a}}$ Abbreviations: VAS, visual ana logue scale; REEDA, redness edema ecchymosis discharge approximation; CI, confidence interval.

$\mathrm{b}$ Data indicate Mean \pm Standard Deviation.

${ }^{\mathrm{C}}$ Number of participants was 54 in each group at baseline and ( $\left.5 \pm 1\right)$ after intervention, and (10 \pm 1$)$ after intervention 54 in each group for pain score and 53 in each group for pain score; for REEDA score Mean difference for the baseline comparison and ( $5 \pm 1$ ) after intervention using independent t-test.

$\mathrm{d} \neq$ : means whitney

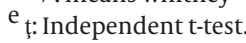

Table 3. Adverse Events During the 10 - Day Period of the Study

\begin{tabular}{lccc}
\hline & $\begin{array}{c}\text { Adverse Events Dur- } \\
\text { ing the 10-Day }\end{array}$ & Placebo Group & Horse Tail Group \\
\hline $\mathbf{1}$ & Nausea & 2 & 2 \\
$\mathbf{2}$ & Vomiting & 1 & 1 \\
\hline $\mathbf{3}$ & Diarrhea & 2 & 1 \\
$\mathbf{4}$ & Urination frequency & 1 & 2 \\
\hline $\mathbf{5}$ & Fever & 5 & 3 \\
\hline $\mathbf{6}$ & Difficulty in walking & 7 & 8 \\
\hline $\mathbf{7}$ & Paresis & 1 & 3 \\
\hline $\mathbf{8}$ & Skin Problems & 3 & 1 \\
\hline
\end{tabular}

\section{Discussion}

The present study results showed that Equisetum Arvense ointment 3\% healed episiotomy wound and reduced its pain intensity within 10 days after delivery. According to review of literature, the present study was the first of its kind assessing the effect of Equisetum Arvense plant on healing human episiotomy wound and reducing intensity of its pain. A study by Ozay et al. in Turkey on the effect of Equisetum Arvense ointment on rats showed increased regeneration of dermis and epidermis and granulation of tissue thickness after 14 days (14). In a study by Ashrafi et al. in Iran, "Histometric and histopathologic evaluation of the effects of Equisetum arvense herbal extract versus zinc oxide in rabbit skin wound healing model", equisetum extract ointment produced the best wound healing. Furthermore, the overall healing result in the second and third weeks was better compared to other groups (13). In another study in Turkey, conducted by Hayat et al. entitled "Effect of Equisetum arvense on wound contraction of full-thickness skin wounds in rabbits", positive effect of equisetum 5\% was observed on wound healing, which could be caused by silicic acid, silicon and saponin (15). A study conducted by Grundemann et al. entitled "Equisetum modulation of immune cells inflammatory function" showed that using equisetum extract produces an anti-inflammato- 
ry effect through interaction with immune cells (21). In Brazil, Do Monte et al. studied analgesic effects of equisetum extract on rats and showed its analgesic effects in chemical models of pain, which was unrelated to the opioid system of this drug (22). Moreover, antidiabetic and urinary creatinine reducing properties of this drug have been shown in rats $(23,24)$. In a study in Healthy Volunteers, Carneiro et al. found that E. arvense extract produced a diuretic effect that was stronger than that of the negative control and was equivalent to that of hydrochlorothiazide without causing significant changes in the elimination of electrolytes (17). Costa Rodrigues et al. found that Equisetum appeared to have a negative effect on human osteoclastogenesis, which is in line with its putative beneficial role in pathophysiological conditions associated with increased osteoclastic activity and might suggest potential utility for treatment with bone regeneration strategies (16). In another study, the results suggested that ethanolic extract of E. arvense seems to possess anxiolytic effect with lower sedative activity than that of diazepam (18). This plant has antimicrobial properties, and its aqueous and ethanol extracts are effective on bacteria such as Staphylococcus aureus, Escherichia coli, Klebsiella pneumoniae, Pseudomonas aeruginosa and Salmonella enteritidis, and fungi such as Aspergillus niger and Candida albicans) (25). No short-term side-effects have been reported for this plant so far. For instance, in a study in Japan entitled "Toxic effects of equisetum plant on F344 rats" conducted by Tago et al. no deaths or clinical symptoms were observed in body weight, urine analysis, hematology or biochemical serum in male and female F344 rats, because of the supplementary powder of equisetum plant (3\%) (26). In a study entitled "Study of acute hepatotoxicity of Equisetum arvense L. in rats", oral treatment with graded doses of Equisetum arvense L. did not lead to hepatic changes (27). Unfortunately, no article was found to clearly show healing and analgesic effects of this plant in human wounds, which made it impossible to compare the present study with other similar studies. Thus, we only discussed articles that showed the effects of this drug on animals. Considering some common compounds in equisetum and Achillea millefolium (echoistine, chemical formula $\mathrm{C}_{6} \mathrm{H}_{6} \mathrm{O}_{6}$ ), the results of some studies are discussed as follows;

A study by Akkol, entitled "Evaluation of the Wound Healing Potential of Achillea biebersteinii Afan. (Asteraceae) by In Vivo Excision and Incision Models" showed histopathological examination supported the outcome of linear incision and circular excision wound models as well (28). A study by Potrich et al. showed gastroprotective activity of Achillea millefolium extract (29). In relation to adverse effects of this herbal drug 10 days after use, other than walking difficulty and muscle weakness, the remaining adverse effects were more prevalent in placebo group or the same as intervention group. These two cases were referred to the resident in the study clinic. In the opinion of senior resident, muscle weakness was as- sociated with general physical weakness of the patient, for which supplementary drugs were administered, and walking problem was thought to be due to the pain in episiotomy site, for which diclofenac suppository was administered. In telephone follow-up, these problems had been resolved. It is suggested to assess beneficial effects of this drug in further investigations.

\section{Acknowledgements}

I appreciate the head and Midwifes of Alzahra Hospital cooperation in performing this study, Research and Technology Deputy of Tabriz University of Medical Sciences for financial support and all the mothers helped us in this study.

\section{Authors' Contributions}

Soheila Bani and Shirin Hasanpoor participated in design and data collection and writing the manuscript. Azam Asgharikhatooni participated in design and data collection, analysis and writing the manuscript. Sakineh Mohammad Alizade helped in design statistical analysis and writing the manuscript and Yusef Javadzadeh prepared the Equisetum Arvense Ointment and placebo and writing the manuscript.

\section{Funding/Support}

The study was supported by Tabriz University of Medical Sciences.

\section{References}

1. Carroli G, Mignini L. Episiotomy for vaginal birth. Cochrane Database Syst Rev. 2009(1):CD000081.

2. Lam KW, Wong HS, Pun TC. The practice of episiotomy in public hospitals in Hong Kong. Hong Kong Med J. 2006;12(2):94-8.

3. Trinh AT, Khambalia A, Ampt A, Morris JM, Roberts CL. Episiotomy rate in Vietnamese-born women in Australia: support for a change in obstetric practice in Viet Nam. Bull World Health Organ. 2013;91(5):350-6.

4. Izuka E, Dim C, Chigbu C, Obiora-Izuka C. Prevalence and predictors of episiotomy among women at first birth in enugu, SouthEast Nigeria. Ann Med Health Sci Res. 2014;4(6):928-32.

5. Graham ID, Carroli G, Davies C, Medves JM. Episiotomy rates around the world: an update. Birth. 2005;32(3):219-23.

6. Khajvy Shojaei KK, Davaty A, Zayeri F. Complication and related factors in epithelial episiotomy primiparous referred to hospital in Tehran: a longitudinal study for three months.J Urmia Nurs Midwifery Fac. 2009;7(4):2.17e25.

7. Thacker SB. Midline versus mediolateral episiotomy. BMJ. 2000;320(7250):1615-6.

8. Karacam Z, Ekmen H, Calisir H, Seker S. Prevalence of episiotomy in primiparas, related conditions, and effects of episiotomy on suture materials used, perineal pain, wound healing 3 weeks postpartum, in Turkey: A prospective follow-up study. Iran J Nurs Midwifery Res. 2013;18(3):237-45.

9. Mohammadi A, Mohammad-Alizadeh-Charandabi S, Mirghafourvand M, Javadzadeh Y, Fardiazar Z, Effati-Daryani F. Effects of cinnamon on perineal pain and healing of episiotomy: a randomized placebo-controlled trial. J Integr Med. 2014;12(4):359-66.

10. Bent S. Herbal medicine in the United States: review of efficacy, safety, and regulation: grand rounds at University of California, San Francisco Medical Center.J Gen Intern Med. 2008;23(6):854-9.

11. Salimifar M, Fatehi-Hassanabad Z, Fatehi M. A review on natural 


\section{Asgharikhatooni A et al.}

products for controlling type 2 diabetes with an emphasis on their mechanisms of actions. Curr Diabetes Rev. 2013;9(5):402-11.

12. Volak J, Stodola J. Plantes Medicinales. 5th edTehran: Gognoos; 2008.

13. Ashrafi A, Rezaii A, Sohrabi Haghdost I, Mehdineghad B, Ashraf I, Asmarian SH. Histometric and histophatologic evaluation of the effects of Equistum arvense herbal extract versus zinc oxid in rabbit skin wound healing model. Vet J Tabrize.;4(2):843-53.

14. Ozay Y, Ozyurt S, Guzel S, Cimbiz A, Olgun EG, Cayci MK. Effects of Equisetum arvense ointment on dermal wound healing in rats. Wounds Compend Clin Res Prac. 2010;22(10):261-7.

15. Hayat A, Temamogull F, Yilmaz R, Karabulut O. Effect of Equisetum arvense on Wound Contraction of Full-Thicnes Skin Wounds in Rabbits. J Anim Vet Adv. 2011;10(1):81-3.

16. Costa-Rodrigues J, Carmo SC, Silva JC, Fernandes MH. Inhibition of human in vitro osteoclastogenesis by Equisetum arvense. Cell Prolif. 2012;45(6):566-76.

17. Carneiro DM, Freire RC, Honorio TC, Zoghaib I, Cardoso FF, Tresvenzol LM, et al. Randomized, Double-Blind Clinical Trial to Assess the Acute Diuretic Effect of Equisetum arvense (Field Horsetail) in Healthy Volunteers. Evid Based Complement Alternat Med. 2014;2014:760683.

18. Singh N, Kaur S, Bedi PM, Kaur D. Anxiolytic effects of Equisetum arvense Linn. extracts in mice. Indian J Exp Biol. 2011;49(5):352-6.

19. Jiang X, Qu Q, Li M, Miao S, Li X, Cai W. Horsetail mixture on rheumatoid arthritis and its regulation on TNF-alpha and IL-10. PakJ Pharm Sci. 2014;27(6 Suppl):2019-23.

20. Mimica-Dukic N, Simin N, Cvejic J, Jovin E, Orcic D, Bozin B. Phenolic compounds in field horsetail (Equisetum arvense L.) as natural antioxidants. Molecules. 2008;13(7):1455-64.

21. Grundemann C, Lengen K, Sauer B, Garcia-Kaufer M, Zehl M, Hu- ber R. Equisetum arvense (common horsetail) modulates the function of inflammatory immunocompetent cells. BMC Complement Altern Med. 2014;14:283.

22. Do Monte FH, dos Santos JG, Jr., Russi M, Lanziotti VM, Leal LK, Cunha GM. Antinociceptive and anti-inflammatory properties of the hydroalcoholic extract of stems from Equisetum arvense $\mathrm{L}$. in mice. Pharmacol Res. 2004;49(3):239-43.

23. Safiyeh S, Fathallah FB, Vahid N, Hossine N, Habib SS. Antidiabetic effect of Equisetum arvense L. (Equisetaceae) in streptozotocininduced diabetes in male rats. PakJ Biol Sci. 2007;10(10):1661-6.

24. Soleimani S, Azarbaizani FF, Nejati V. The effect of Equisetum arvense L. (Equisetaceae) in histological changes of pancreatic beta-cells in streptozotocin-induced diabetic in rats. PakJ Biol Sci. 2007;10(23):4236-40.

25. Radulovic N, Stojanovic G, Palic R. Composition and antimicrobial activity of Equisetum arvense L. essential oil. Phytother Res. 2006;20(1):85-8.

26. Tago Y, Wei M, Ishii N, Kakehashi A, Wanibuchi H. Evaluation of the Subchronic Toxicity of Dietary Administered Equisetum arvense in F344 Rats. J Toxicol Pathol. 2010;23(4):245-51.

27. Baracho NC, Vicente BB, Arruda GD, Sanches BC, Brito J. Study of acute hepatotoxicity of Equisetum arvense L. in rats. Acta Cir Bras. 2009;24(6):449-53.

28. Akkol EK, Koca U, Pesin I, Yilmazer D. Evaluation of the Wound Healing Potential of Achillea biebersteinii Afan. (Asteraceae) by In Vivo Excision and Incision Models. Evid Based Complement Alternat Med. 2011;2011:474026.

29. Potrich FB, Allemand A, da Silva LM, Dos Santos AC, Baggio $\mathrm{CH}$ Freitas CS, et al. Antiulcerogenic activity of hydroalcoholic extract of Achillea millefolium L.: involvement of the antioxidant system.J Ethnopharmacol. 2010;130(1):85-92. 